\title{
Qualitative thallium urinary assays are almost as valuable as quantitative tests: implication for outpatient settings in low and middle income countries
}

\author{
Amir Ghaderi ${ }^{1}$, Hamid Reza Banafshe ${ }^{2}$, Soroor Khodabandehlo ${ }^{3}$, Fateme Mehrzad ${ }^{4}$, Omid Mehrpour ${ }^{5}$, Reza \\ Afshari ${ }^{6,7}$
}

${ }^{1}$ Ph.D. Student of Addiction Studies, Physiology Research Center, Department of Addiction Studies, School of Medicine, Kashan University of Medical Sciences, Kashan, Iran

${ }^{2}$ Ph.D. of Pharmacology, Associate Professor, Physiology Research Center, Department of Pharmacology, School of Medicine, Kashan University of Medical Sciences, Kashan, Iran

${ }^{3}$ B.Sc. of Occupational Health, Department of Occupational Health, School of Health, Kurdistan University of Medical Sciences, Sanandaj, Iran

${ }^{4}$ M.D., Psychiatrist, Department of Psychiatry, School of Medicine, Kashan University of Medical Science, Kashan, Iran

${ }^{5}$ M.D., Fellowship of Medical Toxicology, Associate Professor, Medical Toxicology and Drug Abuse Research Center (MTDRC), Birjand University of Medical Sciences (BUMS), Iran

${ }^{6}$ M.D, MPH, M.Sc., Ph.D., BC Centre for Disease Control, Vancouver, Canada

${ }^{7}$ Professor of Clinical Toxicology, Addiction Research Centre, Mashhad University of Medical Sciences, Mashhad, Iran

Type of article: Original

\begin{abstract}
Background: Thallium ( $\mathrm{Tl}$ ), lead and steroid exposures were reported as a result of street drug consumption such as heroin and cocaine.

Objective: This study aimed to compare the values of qualitative and quantitative assays for detecting $\mathrm{Tl}$ as an adulterant in opioid-like compound drug users.

Methods: This case-control study was conducted throughout a specified time bracket ranging from May 2015 to November 2015 in Imam Reza Hospital, Mashhad, Iran. In general, urine thallium samples for 100 opioid overdosed subjects with a history of chronic opioid use and 50 non-drug users were studied. Qualitative 24 hoursurinary-thallium-level (QL) and quantitative 24 hours-urinary-thallium-level (QT) were conducted in both groups. Independent-samples t-test and Spearman's Coefficient were applied for analytical purposes. SPSS software 16 was used to conduct statistical analyses with P values less than 0.05 regarded as significant.

Results: A total of 150 cases were studied. Raw opium users accounted for $66 \%$ of the cases followed by mixed (28\%) and heroin users (6\%). Mean (SD) QT level for QL was $26.8(1) \mu \mathrm{g} / \mathrm{L}$, while it was $2.3 \mu \mathrm{g} / \mathrm{L}(0.4 \mu \mathrm{g} / \mathrm{L})$ for negative $\mathrm{QL}$, which was far below QL positive cases $(\mathrm{p}=0.002)$. The qualitative test showed more accuracy at higher quantitative levels. In all cases, qualitative test was fully sensitive $(100 \%)$, highly specific $(89 \%)$ with a positive likelihood ratio (PLR) of 9.1 and a negative likelihood ratio (NLR) of 0.

Conclusion: These results suggest that qualitative assays could be used with confidence in assessing Tl exposure in drug users. Physicians may easily and confidently use Tl qualitative tests in rehabilitation centers, where toxicology laboratories may not be available.
\end{abstract}

Keywords: Drug user, Thallium, Quantitative assay, Qualitative assay

\section{Introduction}

Thallium (Tl) is a systemic, metallic toxicant, which has high affinity with sulphydryl groups of cells and potassium binding sites throughout the body $(1,2)$. Alopecia, painful peripheral neuropathy, toxic encephalopathy,

\section{Corresponding author:}

Professor Dr. Reza Afshari, Addiction Research Centre, Mashhad University of Medical Sciences, Mashhad, Iran. Tel: +98.5138598973; Fax: +98.5138420305; Email: AfshariR@mums.ac.ir

Received: November 17, 2016, Accepted: March 11, 2017, Published: April 2017

iThenticate screening: March 03, 2017, English editing: March 29, 2017, Quality control: April 07, 2017

(C) 2017 The Authors. This is an open access article under the terms of the Creative Commons Attribution-NonCommercialNoDerivs License, which permits use and distribution in any medium, provided the original work is properly cited, the use is non-commercial and no modifications or adaptations are made. 
gastrointestinal symptoms and visual disturbances are the characteristic manifestations following $\mathrm{Tl}$ exposure $(3,4)$. $\mathrm{Tl}$ is responsible for several types of intoxications, nonetheless, a toxicological profile for $\mathrm{Tl}$ in humans has not been recently updated (5-7). Thallium is abnormal to be detected in the human body irrespective of the level. Yet, It is considered as dangerous when reaching $10-15 \mathrm{mg} / \mathrm{kg}$ of body weight (8-10). Tl influx into the cell resembles potassium as these two elements share a common charge and ionic radius. Furthermore, Tl exerts an inhibitory effect on Na-k ATPase while binding to sulfhydryl groups (11). Opioids constitute common drugs used at a national level in Iran, ranging from opioid (82\%), to opium ashes (28\%), methadone for non-medical usages $(16.6 \%)$, heroin and heroin/cracked (16\%), morphine (2.6\%) (12). In this respect, thallium has been identified as an infamous adulterant added by street druggists to opioids, heroin and cocaine, leading to intoxication at varying levels (13-16). To date, drug adulteration such as lead, $\mathrm{Tl}$ and steroid concurrent toxicities have not been investigated in admitted opioid overdose cases with history of drug use (17). Substance use is a major public health hazard across the globe. In Iran, where people believe that opioid consumption may prevent cardiovascular diseases, hypertension, and diabetes, is a problem looming larger than ever $(18,19)$. In previous articles, we reported clinical and preclinical findings of opioid and heroin poisoned patients with thallium exposure as an adulterant $(13,16)$. $\mathrm{Tl}$ in urine could be measured in qualitative and quantitative terms. In this study, we tried to evaluate qualitative Tl 24 hours' urine tests (QL) compared to quantitative $\mathrm{Tl}$ urine levels (QT) in case and control groups.

\section{Material and Methods}

\subsection{Patients and design}

This case-control study was done from May to November 2015. One hundred opioid users for more than three years, aged 18 to 65 years old, who referred to Imam Reza Hospital were compared with 50 a matching sex and age group of opioid naïve controls. Cases with history of diphenoxylate, acetaminophen codeine and tramadol use were excluded. Using immunoassay tests, we tested urinary morphine to confirm opioid drug use.

\subsection{Laboratory assessment}

Milliliter urine was gathered from 24-hour urinary samples of patients and kept in $100 \mathrm{~mL}$ polyethylene containers at $-20^{\circ} \mathrm{C}$. First, 24-hour urinary samples were examined for $\mathrm{Tl}$ in the two groups using a qualitative (semiquantitative) and quantitative assays.

2.2.1. Qualitative analysis $(Q L)$ :

Based on semi-quantitative Tl-screening test, $<50 \mu \mathrm{g} / \mathrm{L}$ was considered negative, trace $(50-100 \mu \mathrm{g} / \mathrm{L}),+1(100-200$ $\mu \mathrm{g} / \mathrm{L}),+2(200-300 \mu \mathrm{g} / \mathrm{L}),+3(300-400 \mu \mathrm{g} / \mathrm{L})$, and $+4(>400 \mu \mathrm{g} / \mathrm{L})(13)$.

2.2.2. Quantitative analysis $(Q T)$ :

$\mathrm{Tl}$ concentration in urine was quantitatively measured using graphite furnace atomic absorption spectrometry (Perkin Elmer, Model 3030 with HGA 400 Programmer) (20). We used a Tl standard solution, Tl (I) nitrate in nitric acid $0.5 \mathrm{~mol} / \mathrm{L}\left(1000 \mathrm{mg} / \mathrm{L}\right.$; Tl Certipur ${ }^{\circledR}$, Merck, USA). To measure $\mathrm{Tl}$ in urine, the liquid phase was separated from the sediment after extraction with nitric acid, sulfuric acid, and Triton X-100. To prevent graphite tube damage, $2 \%$ ammonium monovanadate was added to $1 \%$ sodium hydroxide. We centrifuged the solution at high speed for five minutes, and $25 \mu \mathrm{L}$ from the supernatant was injected into the graphite. The absorbance rate was measured at $276.8 \mathrm{~nm}$ similar to previous studies $(21,22)$. Quantitative analysis considered to be the diagnostic gold standard, and the value of qualitative assays were compared to this reference.

\subsection{Statistical analysis}

Independent-samples t-test and Spearman's coefficient test were run using SPSS 16 (SPSS Inc., Chicago, Illinois, USA) (23). P-value less than 0.05 was considered statistically significant.

\section{Results}

\subsection{Qualitative and quantitative tests of urinary Tl level}

The mean (SD) quantitative urinary Tl levels in cases and controls were $21(53) \mu \mathrm{g} / \mathrm{L}$ and 1 (1) $\mu \mathrm{g} / \mathrm{L}$, which was significantly different $(\mathrm{p}<0.001)$. In total, $85 \%$ of urine samples were negative for $\mathrm{Tl}$ when tested with qualitative assay. Using QT test, the mean urinary Tl level was $26.8(1) \mu \mathrm{g} / \mathrm{L}$ in the positive cases that were determined with QL test. Mean QT urinary Tl level was $2.3(0.4) \mu \mathrm{g} / \mathrm{L}$ in the QL determined negative cases, which was significantly lower than QL positive cases ( $\mathrm{p}=0.002)$. Quantitative tests in $114(76 \%)$ of the cases were below acceptable levels consistent with negative qualitative results (Table 1). The QT results were not normal in 25 (17\%) of the samples (5$50 \mu \mathrm{g} / \mathrm{L}$ ). Among them, qualitative tests were negative for 14 cases that account for $56 \%$. Qualitative tests for the rest of them $(n=11)$ were observed to be trace (seven cases) or $+1,+2$, and +3 (four cases) (Table 2). For $11(7.3 \%)$ 
http://www.ephysician.ir

samples, the result of the quantitative test was abnormal ( $\geq 50 \mu \mathrm{g} / \mathrm{L})$. Qualitative test results were $+1,+2$, or +3 in all these cases (Table 2).

\subsection{Diagnostic associations}

In all cases, qualitative test was fully sensitive (100\%), highly specific (89\%) with a positive likelihood ratio (PLR) of 9.1 and a negative likelihood ratio (NLR) of 0 (Table 3). Among the cases, sensitivity and specificity were $100 \%$ with a PLR of 5.5. and an NLR of 0 . In the control group, sensitivity and specificity were estimated to be $100 \%$ with an infinite PLR and an NLR of zero (Table 3).

Table 1. Outcomes related to qualitative and quantitative tests $(n=150)$

\begin{tabular}{|l|l|l|l|l|l|}
\hline \multicolumn{2}{|l|}{ Group } & \multicolumn{2}{|l|}{ Qualitative test; $(\%)$} & \multirow{2}{*}{ Total } \\
\cline { 3 - 6 } \multicolumn{2}{l|}{} & Negative & Trace & $+1,+2,+3$ & \\
\hline \multirow{2}{*}{ Quantitative Test } & Below Acceptable Level $(5-50 \mu \mathrm{g} / \mathrm{L})$ & $114(76)$ & $0(0)$ & $0(0)$ & $114(76)$ \\
\cline { 2 - 6 } & Above Acceptable Level $(\geq 50 \mu \mathrm{g} / \mathrm{L})$ & $14(9.3)$ & $7(4.7)$ & $15(10)$ & $36(24)$ \\
\hline Total & $128(85.3)$ & $7(4.7)$ & $15(10.0)$ & $150(100)$ \\
\hline
\end{tabular}

Table 2. Results of the qualitative and quantitative tests by separation of the control and case groups

\begin{tabular}{|c|c|c|c|c|c|c|}
\hline \multicolumn{3}{|l|}{ Group } & \multicolumn{3}{|c|}{ Qualitative test; n (\%) } & \multirow[t]{2}{*}{ Total } \\
\hline & & & Negative & Trace & $+1,+2,+3$ & \\
\hline \multirow[t]{3}{*}{ Case } & \multirow[t]{3}{*}{ Quantitative test } & Negative & $66(66)$ & $0(0)$ & $0(0)$ & $66(66)$ \\
\hline & & Positive & $14(14)$ & $6(6.0)$ & $14(14)$ & $34(34)$ \\
\hline & & Total & $80(80)$ & $6(6.0)$ & $14(14)$ & 100 \\
\hline \multirow[t]{3}{*}{ Control } & \multirow[t]{3}{*}{ Quantitative test } & Negative & $48(48)$ & $0(0)$ & $0(0)$ & $48(96)$ \\
\hline & & Positive & $0(0)$ & $1(1.0)$ & $1(1)$ & $2(4)$ \\
\hline & & Total & $48(48)$ & $1(1.0)$ & $1(1)$ & $50(100)$ \\
\hline
\end{tabular}

Table 3. Diagnostic tests

\begin{tabular}{|c|c|c|c|c|}
\hline \multirow{2}{*}{\multicolumn{2}{|c|}{ Test }} & & \multicolumn{2}{|c|}{ Quantitative Test*; n (\%) } \\
\hline & & & Negative & Positive \\
\hline \multirow[t]{6}{*}{ Qualitative test } & Negative & \multirow[t]{2}{*}{ Total samples } & $114(76)$ & $14(9.3)$ \\
\hline & Positive & & $0(0)$ & $22(14.7)$ \\
\hline & Negative & \multirow[t]{2}{*}{ Control group } & $66(66)$ & $14(14)$ \\
\hline & Positive & & $0(0)$ & $20(20)$ \\
\hline & Negative & \multirow[t]{2}{*}{ Case group } & $48(96)$ & $0(0)$ \\
\hline & Positive & & $0(0)$ & $2(2)$ \\
\hline
\end{tabular}

*Quantitative test assumed to be the standard.

\section{Discussion}

This study found that QL is highly sensitive and specific when compared to QT in determining thallium levels in urine. The value of this test extends to both opioid overdosed and naïve subjects. Qualitative assays could be a good surrogate for quantitative tests. Iran's neighbour Afghanistan, has been the biggest producer of opioids worldwide for many years, as well as having a long history of opioid use. This has resulted in similar complications when compared to other countries $(24,25)$. It has been shown that street drug smugglers and dealers add other medications and heavy metals such as lead or Tl to magnify the effects or increase the weight of drugs for financial gains (26, 27). This may lead to serious but subtle toxicities. Following a case report by Questel et al. (14), an outbreak of Tl exposure in chronic opioid users was reported by Afshari et al. (13) from Iran in which recurrent symptoms of thallotoxicosis were attributed to adulterated street drug use (13). There could be found a statistically significant difference between the case and control groups in both quantitative and qualitative analyses reports; nevertheless, inconsistencies were detected, making definitive diagnosis less likely if not impossible. According to qualitative urinary $\mathrm{Tl}$ findings, $85 \%$ of the cases were negative for $\mathrm{Tl}$, which could be accounted for by the fact that the $\mathrm{Tl}$ level might not be identified in urine or blood. False, normal or low levels of thallium urine were seen less in cases whose 24-hour urine samples were taken, making it a more reliable method of detection compared to blood sampling with higher falsehood rates (28). There are three phases to be seen in acute Tl poisoning. Primarily, the element spreads intravascularly within the first few hours. It subsequently propagates through the central nervous system for the following two days. The third phase regards elimination mainly via GI and renal system, after another 24 hours (29). 
Thallium poisoning is a serious health problem with many complications from gastroenterological to neurological and dermatological manifestations $(30,31)$. The most common manifestations pertaining to $\mathrm{Tl}$ intoxication among drug abusers include neuropathy (both sensory and motor), tremor, ataxia, dry skin, scalp hair loss, sweating, vomiting, nausea, constipation, paresis, polyneuropathy, abdominal pain and alopecia $(9,30,32)$. The clinical signs and symptoms pertaining to Tl poisoning may vary based on dosage, body weight, individual susceptibility, and the onset of treatment (28). Combined assays were proven superior to single methods in their specificity and sensitivity. To enhance survival rates and minimize deficits, it seems essential to use more reliable and efficient methods of toxicity detection along with proper clinical management of the given condition. Given the importance of recognition of $\mathrm{Tl}$ as a harmful heavy metal in consumed opiates, the findings of the current study may improve the methods of heavy metal adulteration detection. This study and the related findings can be of benefit in line enhancing metal adulteration techniques, efficacy and reliability, given the common detection of such heavy elements in consumed opiates. In all, it is safe to assume that qualitative methods can replace quantitative ones thanks to their higher sensitivity, specificity and PLR as well as small NLR. This study is subject to certain limitations including incontinency pertaining to opioid concentration and the dose of the drug used by street drug abusers. The highest sensitivity and specificity were proved for quantitative methods, implying that they are considered as gold standard detection methods.

\section{Conclusions}

In settings that opioid use and overdose are common, and $\mathrm{Tl}$ has been reported as an adulterant across a country such as Iran, testing symptomatic opioid users for $\mathrm{Tl}$ should be emphasised. Quantitative measurement of $\mathrm{Tl}$ is preferred; however, toxicology laboratories may not be widely accessible in less well-off regions. This study found that qualitative assays are almost as sensitive and specific as quantitative assays, which has led us to support their use. The applied benefit of this study may extend to rehabilitation centres, where physicians can use available qualitative assays to detect $\mathrm{Tl}$.

\section{Acknowledgments:}

This research was supported by the Physiology Research Center, Kashan University of Medical Sciences. (KAUMS/95121). In addition, extensive cooperation by Dr. Morad Rasouli-Azad is highly appreciated.

\section{Conflict of Interest:}

There is no conflict of interest to be declared.

\section{Authors' contributions:}

All authors contributed to this project and article equally. All authors read and approved the final manuscript.

\section{References:}

1) Ewers U. Environmental exposure to thallium. Sci Total Environ. 1988; 71(3): 285-92. doi: 10.1016/00489697(88)90199-4. PMID: 3043654.

2) Nriagu JO. Thallium in the Environmen( Advances in environmental science and technology). 1998.

3) Hirata M, Taoda K, Ono-Ogasawara M, Takaya M, Hisanaga N. A probable case of chronic occupational thallium poisoning in a glass factory. Ind Health. 1998; 36(3): 300-3. doi: 10.2486/indhealth.36.300. PMID: 9701911.

4) Schaller KH, Manke G, Raithel HJ, Bühlmeyer G, Schmidt M, Valentin H. Investigations of thalliumexposed workers in cement factories. Int Arch Occup Environ Health. 1980; 47(3): 223-31. doi: 10.1007/bf00381680. PMID: 7461849.

5) Venkatesha VT, Viswakanth B, Shruthi P, Shreedhar NC, Sujatha PL. To Death by Thallium-A Case of Thallium Poisoning. Journal of the Indian Society of Toxicology. 2013; 9(2): 44-6.

6) Li S, Huang W, Duan Y, Xing J, Zhou Y. Human fatality due to thallium poisoning: autopsy, microscopy, and mass spectrometry assays. J Forensic Sci. 2015; 60(1): 247-51. doi: 10.1111/1556-4029.12623. PMID: 25407479.

7) Saddique A, Peterson CD. Thalium poisoning: A review. Vet Hum Toxicol. 1983; 25(1): 16-22. PMID: 6338655.

8) Cvjetko P, Cvjetko I, Pavlica M. Thallium toxicity in humans. Arh Hig Rada Toksikol. 2010; 61(1): 111-9. doi: 10.2478/10004-1254-61-2010-1976. PMID: 20338874.

9) Lech T, Sadlik JK. Thallium intoxication in humans. Toxicol Lett. 2007; 172: S85. doi: 10.1016/j.toxlet.2007.05.239. 
10) Galván-Arzate S, Santamaría A. Thallium toxicity. Toxicol Lett. 1998; 99(1): 1-3. PMID: 9801025.

11) Hoffman RS. Thallium toxicity and the role of Prussian blue in therapy. Toxicol Rev. 2003; 22(1): $29-40$. doi: 10.2165/00139709-200322010-00004. PMID: 14579545.

12) Eskandarieh S, Hajebi A, Noroozi A, Haghdoost AA, Baneshi MR. Epidemiology of Alcohol Abuse in Iran. Asia Pac J Med Toxicol. 2014; 3(1): 22. doi: 10.22038/APJMT.2014.2905.

13) Afshari R, Mégarbane B, Zavar A. Thallium poisoning: one additional and unexpected risk of heroin abuse. Clin Toxicol (Phila). 2012; 50(8): 791-2. doi: 10.3109/15563650.2012.713110. PMID: 22889036.

14) Questel F, Dugarin J, Dally S. Thallium-contaminated heroin. Ann Intern Med. 1996; 124(6): 616. doi: 10.7326/0003-4819-124-6-199603150-00024. PMID: 8597335.

15) Insley BM, Grufferman S, Ayliffe HE. Thallium poisoning in cocaine abusers. Am J Emerg Med. 1986; 4(6): 545-8. doi: 10.1016/S0735-6757(86)80016-X. PMID: 3778602.

16) Ghaderi A, Vahdati-Mashhadian N, Oghabian Z, Moradi V, Afshari R, Mehrpour O. Thallium exists in opioid poisoned patients. Daru. 2015; 23: 39. doi: 10.1186/s40199-015-0121-x. PMID: 26231176, PMCID: PMC4521340.

17) Koushesh HR, Afshari R, Afshari R. A new illicit opioid dependence outbreak, evidence for a combination of opioids and steroids. Drug Chem Toxicol. 2009; 32(2): 114-9. doi: 10.1080/01480540802588485. PMID: 19514947.

18) Mohammady GA, Darabi Amin M, Sabet Jahromi MJ, Sheibani H, Nasry M, Malek Puor Afshar R. effect of opium addiction on lipid profile and atherosclerosis among normal and hyperchoLesterolemic rabbits. J Diabetes Metab Disord. 2007; 6: 3.

19) Massomi M, Shahesmaeili A, Mirzazadeh A, Tavakoli M, Ali AZ. Opium addiction and severity of coronary artery disease: a case-control study. J Res Med Sci. 2010; 15(1): 27-32. PMID: 21526055 , PMCID: PMC3082781.

20) Ediger RD. Atomic absorption analysis with the graphite furnace using matrix modification. Atomic Absorption Newsletter. 1975; 14(5): 127-30.

21) Christian GD, Purdy WC. Coulometric determination of thallium in blood and urine. Am J Clin Pathol. 1966; 46(2): 185-8. doi: 10.1093/ajcp/46.2.185. PMID: 5912482.

22) Savory J, Roszel NO, Mushak P, Sunderman FW. Measurements of thallium in biologic materials by atomic absorption spectrometry. Am J Clin Pathol. 1968; 50(4): 505-9. doi: 10.1093/ajcp/50.4.505. PMID: 4300164.

23) Nie NH, Bent DH, Hull CH. SPSS: Statistical package for the social sciences. New York: McGraw-Hill; 1970.

24) Karrari P, Mehrpour O, Afshari R, Keyler D. Pattern of illicit drug use in patients referred to addiction treatment centres in Birjand, Eastern Iran. J Pak Med Assoc. 2013; 63(6): 711-6. PMID: 23901670.

25) Mehrpour O, Karrari P, Sheikhazadi A. Survey of factors related to criminal behavior in a sample of Iranian substance abusers. J Forensic Leg Med. 2013; 20(8): 1078-81. doi: 10.1016/j.jflm.2013.09.022. PMID: 24237824.

26) Karrari P, Mehrpour O, Abdollahi M. A systematic review on status of lead pollution and toxicity in Iran; Guidance for preventive measures. Daru. 2012; 20(1): 2. doi: 10.1186/1560-8115-20-2. PMID: 23226111, PMCID: PMC3514537.

27) Mehrpour O, Karrari P, Abdollahi M. Chronic lead poisoning in Iran; a silent disease. Daru. 2012; $20(1): 8$. doi: 10.1186/2008-2231-20-8. PMID: 23351197, PMCID: PMC3555738.

28) Murray L. Goldfrank's Toxicologic Emergencies, 7th edition. Emerg Med Australas. 2004; 16(1): 87. doi: 10.1111/j.1742-6723.2004.00549.x. PMID: 15239763.

29) Cavanagh JB. What have we learnt from Graham Frederick Young? Reflections on the mechanism of thallium neurotoxicity. Neuropathol Appl Neurobiol. 1991; 17(1): 3-9. doi: 10.1111/j.13652990.1991.tb00687.x. PMID: 2057049.

30) Misra UK, Kalita J, Yadav RK, Ranjan P. Thallium poisoning: emphasis on early diagnosis and response to haemodialysis. Postgrad Med J. 2003; 79(928): 103-5. doi: 10.1136/pmj.79.928.103. PMID: 12612328, PMCID: PMC1742612.

31) Mulkey JP, Oehme FW. A review of thallium toxicity. Vet Hum Toxicol. 1993; 35(5): 445-53. PMID: 8249271.

32) Jha S, Kumar R, Kumar R. Thallium poisoning presenting as paresthesias, paresis, psychosis and pain in abdomen. J Assoc Physicians India. 2006; 54: 53-5. PMID: 16649741. 